Research Article

\title{
Synthesis and Characterization of ZnO-Nanocomposites by Utilizing Aloe Vera Leaf Gel and Extract of Terminalia arjuna Nuts and Exploring Their Antibacterial Potency
}

\author{
Amara Dar, ${ }^{1}$ Rabia Rehman $\mathbb{D}^{2},{ }^{2}$ Warda Zaheer, ${ }^{1}$ Umer Shafique $\mathbb{D}^{0},{ }^{3}$ and Jamil Anwar ${ }^{1,4}$ \\ ${ }^{1}$ Centre for Analytical Chemistry, School of Chemistry, University of the Punjab, Lahore, Punjab, Pakistan \\ ${ }^{2}$ Centre for Inorganic Chemistry, School of Chemistry, University of the Punjab, Quaid-e-Azam Campus, Lahore 54590, Pakistan \\ ${ }^{3}$ Chemistry Department, Government College University, Lahore, Punjab, Pakistan \\ ${ }^{4}$ Chemistry Department, University of Management \& Technology, Lahore, Punjab, Pakistan
}

Correspondence should be addressed to Rabia Rehman; grinorganic@yahoo.com

Received 13 September 2021; Revised 29 September 2021; Accepted 12 October 2021; Published 3 November 2021

Academic Editor: Ajaya Kumar Singh

Copyright (C) 2021 Amara Dar et al. This is an open access article distributed under the Creative Commons Attribution License, which permits unrestricted use, distribution, and reproduction in any medium, provided the original work is properly cited.

Nanotechnology has found vast applications in everyday life. Use of plant extract in the synthesis of nanocomposites produces relatively less toxic and environment-friendly materials. The present study deals with the synthesis of zinc oxide nanocomposite using gel from leaves of Aloe vera (black Aloe vera (BAV) and white Aloe vera (WAV)) and extract from powder of nuts of Terminalia arjuna. Synthesized nanocomposites were then characterized by using SEM, FTIR, and UV-Vis techniques. Disc diffusion method was opted to inquire the antimicrobial ability of nanocomposites against different bacterial strains such as Escherichia coli (-) and Burkholderia stabilis (+). ZnO-BAV possessed good antimicrobial potential against both selected strains as proved from zone of inhibitions. However, $\mathrm{ZnO}-\mathrm{WAV}$ and $\mathrm{ZnO}-\mathrm{N}$ showed potential against E. coli and no response for B. stabilis.

\section{Introduction}

The study and utilization of material at atomic, molecular, and macromolecular scale is an uprising subdiscipline in different fields of science. During nanocomposite synthesis, particle size reduction of metals is a very attractive field for the researchers as it opens different opportunities to produce novel products [1]. There is a remarkable interest in the synthesis of nanoparticles as they exhibit tremendous properties such as rapid disintegration, shorter dissolution time, and organic, inorganic, and organometallic components and can be used for synthesizing nanoparticles.

Electrochemical and physiochemical nature of nanoparticles defines various areas of their applications, such as optics, photonics, chemisensitive sensing, medicine, pharmaceutics, data storage devices, ceramics, and water purification by catalysis and adsorption [1,2]. Synthesis of nanoparticles is generally performed by following two different approaches termed as top-down and bottom-up. In the former method, the macroparticles are reduced to nanosized particles, but they are of nonuniform shape, whereas in the later approach, nanoparticles of definite size, shape, and structure are produced. Green synthesis defines the route to produce nanoparticles using less and relatively safer reagents in order to protect the environment $[3,4]$. Enzymes and biological materials can be utilized as the capping and reducing agents [3]. Nanoparticles can be synthesized by using micro-organisms such as fungi instead of plant extract, and these microorganisms' help to reduce the metals effectively [5].

During recent years, plant-mediated synthesis of metal nanocomposites has gained noticeable popularity [6]. One significant reason is that the plant-mediated synthesis of nanoparticles is relatively faster than microorganism-based synthesis of nanoparticles [7].

It has been already reported that various techniques can be employed for the synthesis of $\mathrm{ZnO}$ nanopowders as thermal decomposition of organic precursor, 
electrodeposition, microwave-assisted techniques, spray pyrolysis, hydrothermal methods, precipitation methods, sol gel method, and use of microemulsions [8-17].

A large variety of plant materials has been used for the synthesis of metal nanocomposites, and their potential antimicrobial effects have also been reported in literature $[18,19]$. In present studies, zinc nanoparticles are synthesized with the help of Aloe vera gel and Terminalia arjuna nuts.

Zinc is a strong reducing agent with a moderately reactive property [20]. $\mathrm{ZnO}$ nanoparticles have promising potential as an antimicrobial agent. It was observed that $\mathrm{ZnO}$ maintains its antibacterial tendency even after composite formation. Its antimicrobial properties include damaging the micro-organism cell by discharge of ions [21]. ZnO composites have also been used as nanofertilizer [22].

Aloe vera is a succulent plant species from the genus Aloe. It has cacti-like leafy structure and mostly found in African and Asian regions. It is used as general tonic for immune system, and its juice can potentially be used to treat various diseases [23, 24]. It is effective in treating lung cancer, diabetes, rheumatic arthritis, ulcers, skin burns, and indigestion; it is used as an anti-inflammatory agent and has cosmological importance [25-29].

Terminalia arjuna belongs to genus Terminalia. This plant is usually located around riverbanks or near the derelict riverbank in South Asia [30-32]. The main chemical constituents of Terminalia nuts include triterpenoids, tannins, saponins, gallic acid, flavonoids, phytosterols, and ellagic acid [33]. Different studies showed that Terminalia arjuna plant exhibits antioxidant potential, hypotensive, anti-inflammatory, antiatherogenic, antimutagenic, anticarcinogenic, and gastroproductive effects. Extracts of this plant has proved it useful against coronary heart diseases.

\section{Materials and Methods}

2.1. Materials. All the chemicals are used in the present study: carbon tetrachloride, silver nitrate, zinc acetate, sodium hydroxide, and chromic acid were obtained from Sigma Aldrich. Furthermore, double distilled water was used for preparing all the solutions.

2.2. Collection of Plant Material. In this study, two plants having medicinal significance were selected, i.e., Aloe vera and Terminalia arjuna. Two varieties of dried Aloe vera gel (commercially available marked as black Aloe vera (BAV) and white Aloe vera (WAV)) were purchased from the local market. The dried plant material was ground to fine powder and sieved through 20 ASTM and kept in a jar for further use.

Almost dried nuts of Terminalia arjuna were directly collected from the trees grown at Quaid-e-Azam Campus, University of the Punjab, Lahore. The nuts were washed, dried, and grounded using a ball mill and sieved through 20 ASTM. The powder was dried at $70^{\circ} \mathrm{C}$ and kept in an air-tight jar for further use.
2.3. Plant Extract Preparation. For the preparation of the plant extract, $5 \mathrm{~g}$ of dried plant material was taken separately in distilled water $(100 \mathrm{~mL})$. They were stirred at $100 \mathrm{rpm}$ on a hot plate for 15 minutes at $70^{\circ} \mathrm{C}$. This solution was filtered after cooling and used for the preparation of $\mathrm{ZnO}$ nanoparticles. Extract of both plant materials was prepared following the same procedure.

2.4. Synthesis of $\mathrm{ZnO}$ Nanocomposites. To synthesize the $\mathrm{ZnO}$ nanomaterial with medicinal plant extracts, initially zinc acetate $(2.9 \mathrm{~g})$ was dissolved in $50 \mathrm{~mL}$ of water. This solution thus obtained was stirred using a magnetic stirrer for 1 hour at room temperature in a conical flask. Then, $20 \mathrm{~mL}$ of $10 \%$ sodium hydroxide solution was slowly added, and the contents were mixed thoroughly. Now, the flask is covered after adding $50 \mathrm{~mL}$ of plant extract and left it for 1 hour. Then, it was placed on an orbital shaker at $100 \mathrm{rpm}$ for 3 hours. Then, the contents were allowed to stand for another 30 minutes. The yellow-coloured $\mathrm{ZnO}$ nanocomposites, settled down at bottom, were separated either by centrifuging or by decanting off the supernatant liquid carefully. The $\mathrm{ZnO}$ composites were dried in an oven at $80^{\circ} \mathrm{C}$ for 2 hours. The scheme used is given in Figure 1 .

2.5. Characterization of $\mathrm{ZnO}$ Nanocomposites. Composite nanoparticles of zinc were characterized by using FTIR, UV, and SEM techniques.

To study the presence of various functional groups, FTIR analysis (Perkin Elmer) was carried out in the range of $4000-400 \mathrm{~cm}^{-1}$ for plant extract and then compared with the plant-based $\mathrm{ZnO}$ nanocomposites.

For conducting the UV analysis, Labomed 3500-UVD was used to find $\lambda_{\max }$ of the synthesized material. They absorb the characteristic wavelengths with a little variation due to the organic molecules from plant materials acting as capping and reducing agents.

To study the surface morphology of any material, SEM analysis was conducted. To verify the formation of nanocomposites, the comparison of SEM of dried plant material and synthesized nanocomposite was studied. It reveals the change in the structural morphology that occurs during the formation of nanocomposites.

\section{Results and Discussion}

3.1. FTIR Analysis of $\mathrm{ZnO}-\mathrm{BAV}$. FTIR spectra of BAV-Zn indicated various bands. Weak signals at $3633 \mathrm{~cm}^{-1}$ are owing to the presence of N-H amines. Strong stretching vibration owing to the formation of $\mathrm{N}-\mathrm{H}$ amides is found at $1533 \mathrm{~cm}^{-1}$. The spectra of $\mathrm{ZnO}-\mathrm{BAV}, \mathrm{ZnO}-\mathrm{WAV}$, and $\mathrm{ZnO}-$ $\mathrm{N}$ are displayed in Figures 2-4.

3.2. FTIR Analysis of $\mathrm{ZnO}-\mathrm{N}$. The presence of secondary amines was displayed due to $\mathrm{N}-\mathrm{H}$ amines at $3343 \mathrm{~cm}^{-1}$. Strong stretching vibrational signals at $1511 \mathrm{~cm}^{-1}$ is owing to the formation of the N-H amide bond. Strong stretching vibration at $1362 \mathrm{~cm}^{-1}$ is because of alpha methyl bending. 


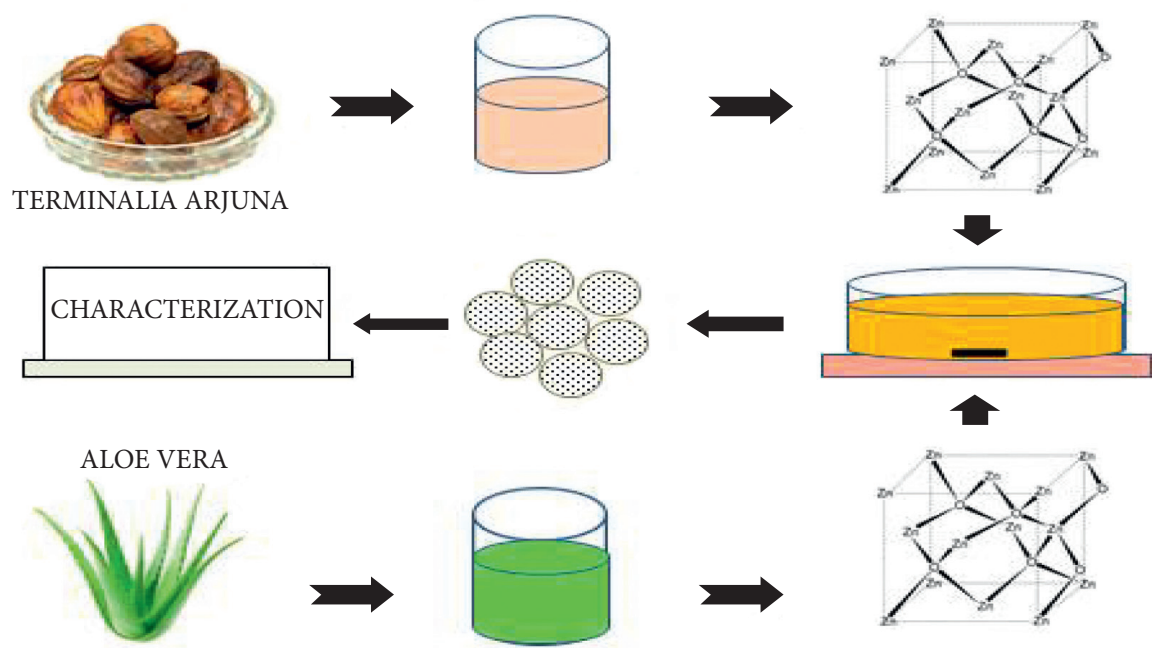

Figure 1: Scheme of synthesis of $\mathrm{ZnO}$ nanocomposites.

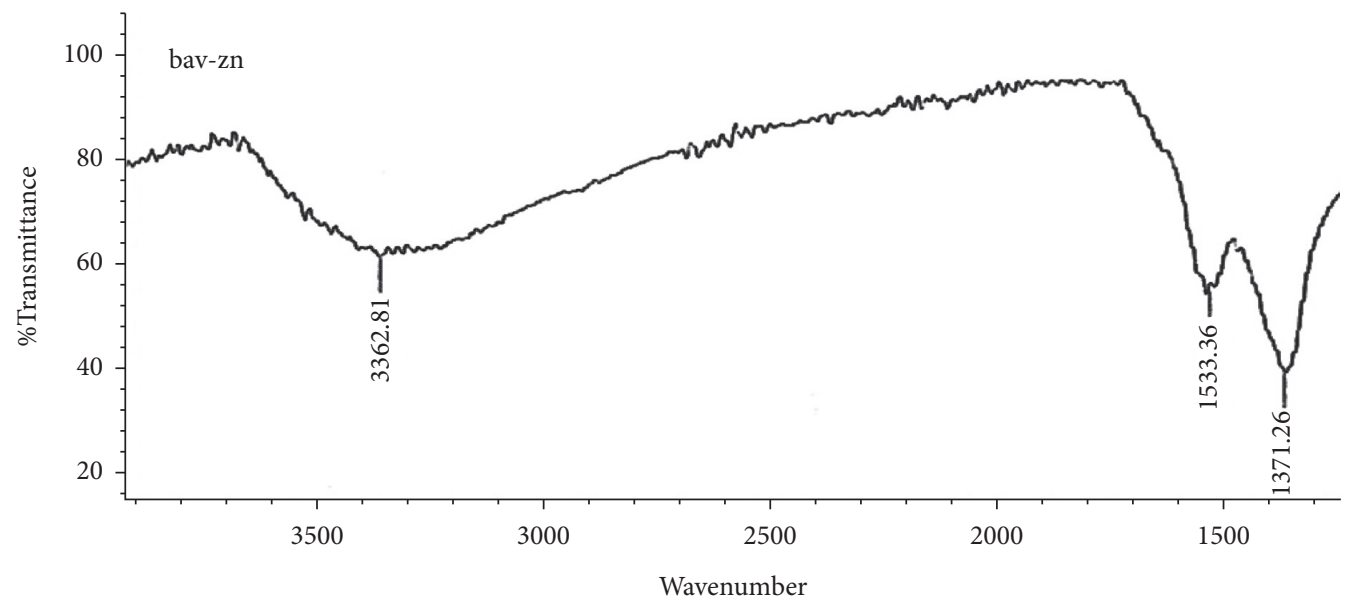

FigURE 2: FTIR spectrogram of ZnO-BAV nanocomposites.

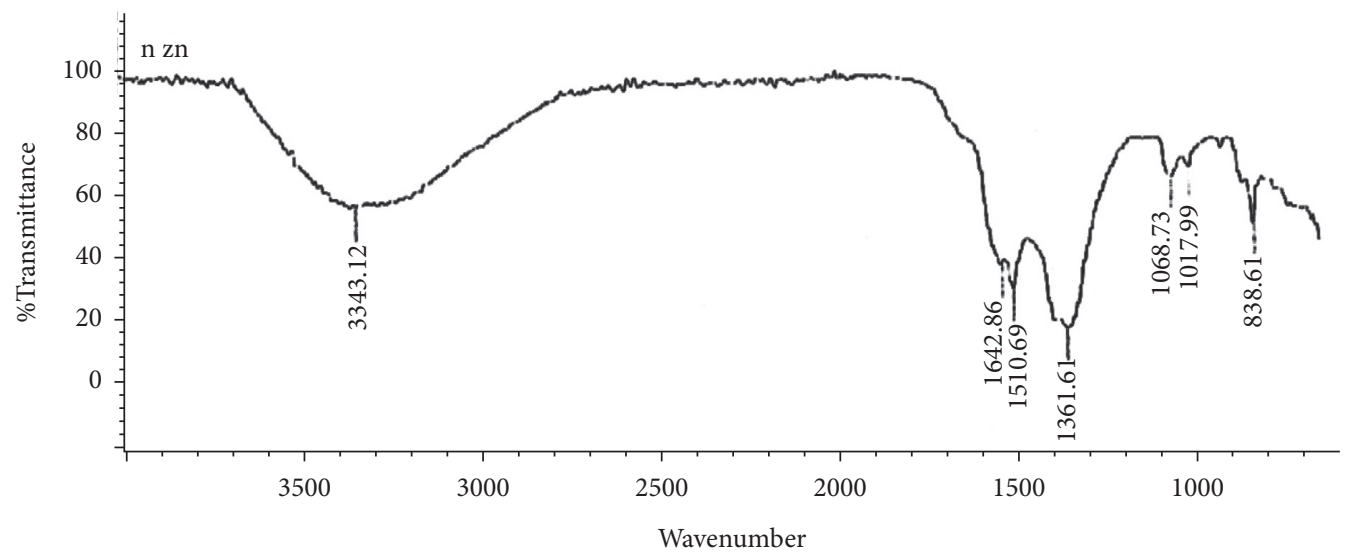

FigURE 3: FTIR spectrogram of $\mathrm{ZnO}-\mathrm{N}$ nanocomposites.

Peak at $1069 \mathrm{~cm}^{-1}$ indicated strong stretching due to oxygen-carbon bond. Band at $838 \mathrm{~cm}^{-1}$ shows strong stretching vibrations caused by the $\mathrm{C}-\mathrm{H}$ bond. The work of Dobrucka also validates our work who found the bands are at 3243 , 2168, 1383,1599, 1076, 780, and $515 \mathrm{~cm}^{-1}$. Peaks near $515 \mathrm{~cm}^{-1}$ can be owing to the stretching vibration of $\mathrm{ZnO}$. 


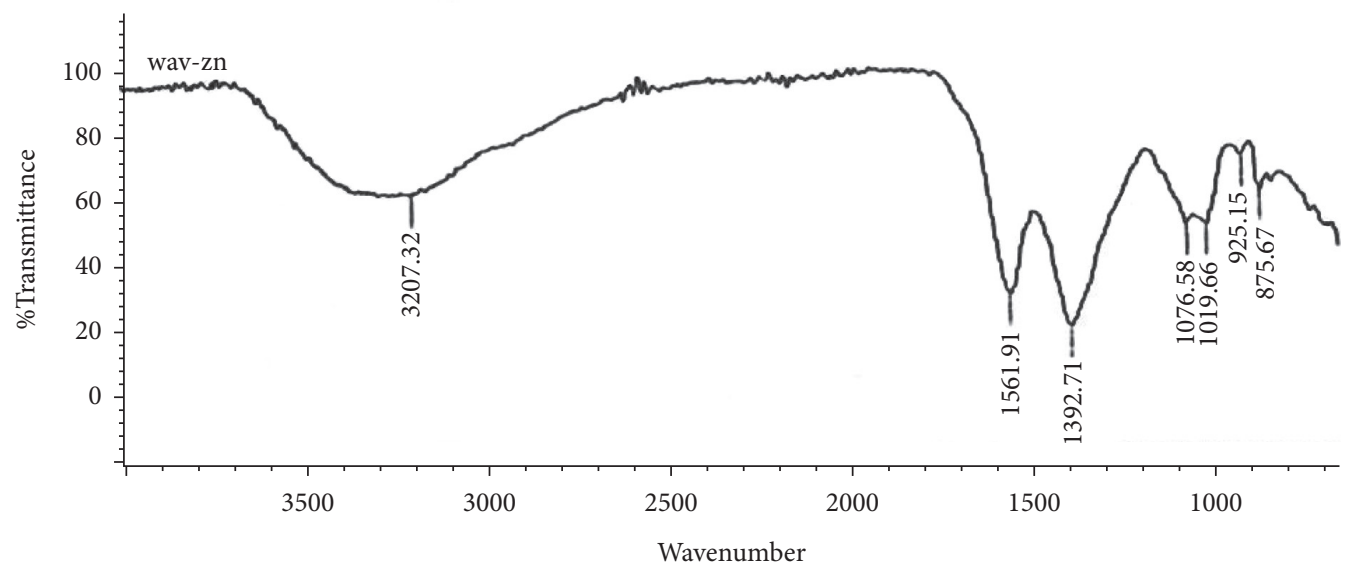

FIGURE 4: FTIR spectrogram of ZnO-WAV nanocomposites.

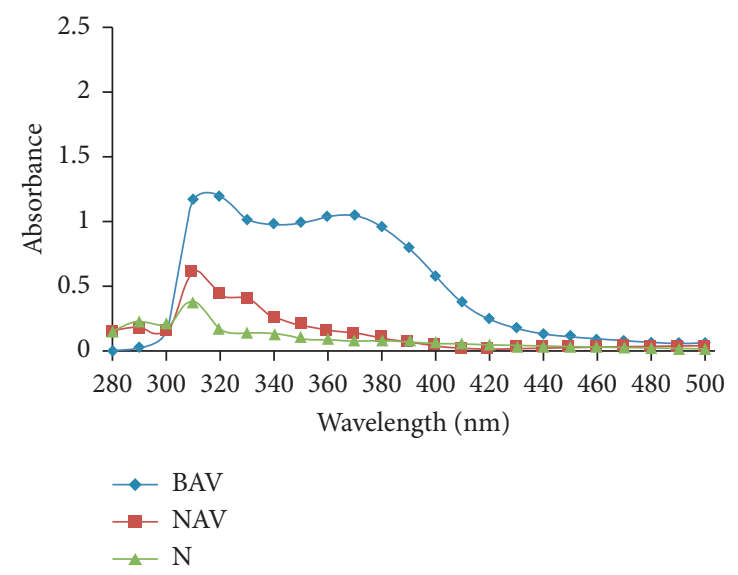

FIgURE 5: UV-Vis spectrogram of $\mathrm{ZnO}$ nanocomposites synthesized by $\mathrm{BAV}$, WAV, and nuts.

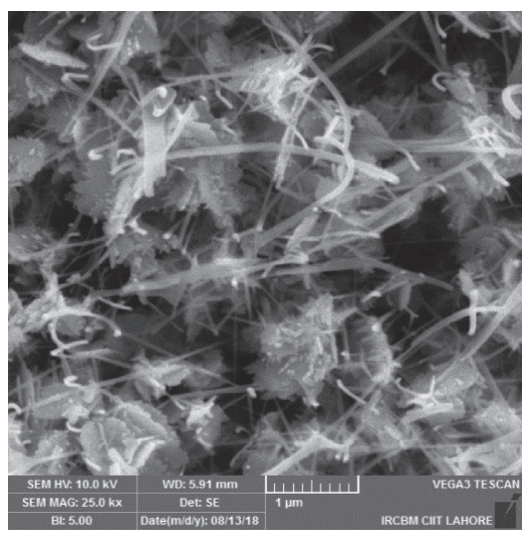

(a)

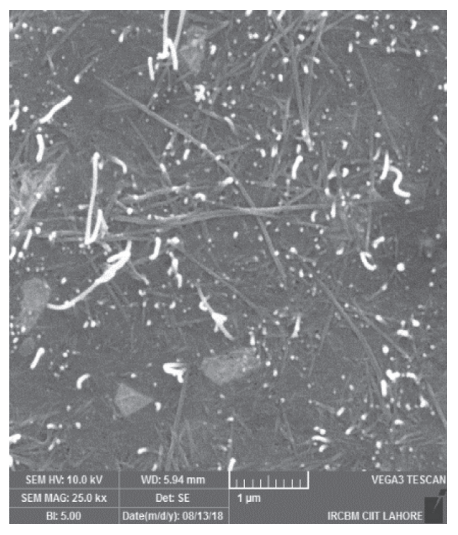

(b)

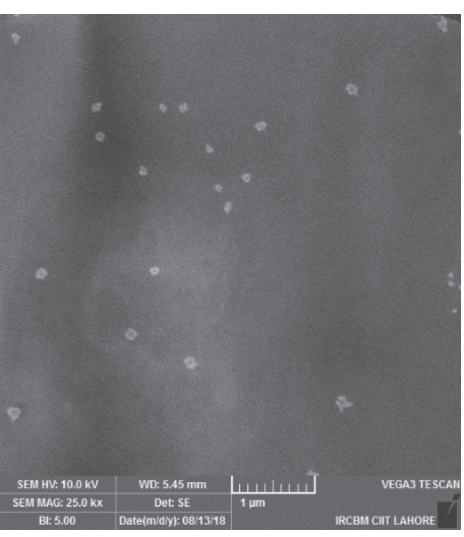

(c)

Figure 6: SEM images of (a) ZnO-BAV, (b) ZnO-N, and (c) ZnO-WAV nanocomposites.

Other bands at 3245 and $1599 \mathrm{~cm}^{-1}$ are indicating the $-\mathrm{OH}$ group. The peaks at 1383 and $1076 \mathrm{~cm}^{-1}$ may be ascribed to -C-O- and -C-O-C-stretching vibes [34].
3.3. FTIR Analysis of $\mathrm{ZnO}-W A V$. In the spectrogram of $\mathrm{ZnO}-\mathrm{WAV}$, the band at $3207 \mathrm{~cm}^{-1}$ demonstrated the presence of amines, whereas the band at $1393 \mathrm{~cm}^{-1}$ is owing 

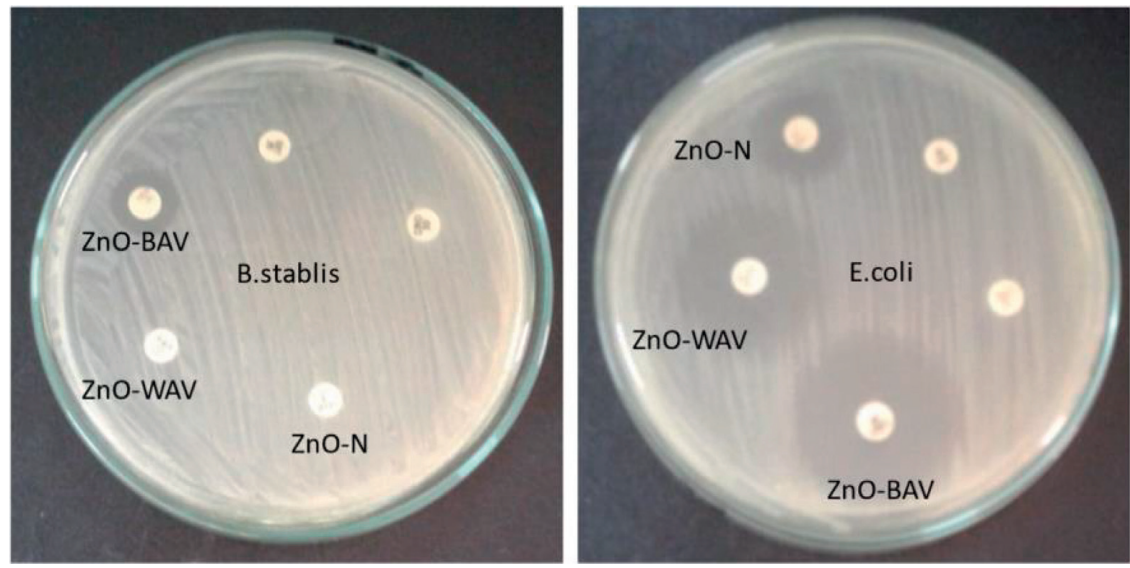

Figure 7: Images showing the application of synthesized nanocomposites of $\mathrm{ZnO}$ by using BAV, WAV, and $\mathrm{N}$ for antibacterial activity against E. coli and B. stabilis.

TABle 1: Zone of inhibition produced by different $\mathrm{ZnO}$ nanocomposites.

\begin{tabular}{lcc}
\hline Nanocomposites & \multicolumn{2}{c}{$\begin{array}{c}\text { Zone of inhibitions for zinc } \\
\text { nanocomposites }\end{array}$} \\
& Escherichia coli & Burkholderia stabilis \\
\hline ZnO-BAV & $0.24 \pm 0.02$ & $0.11 \pm 0.01$ \\
ZnO-WAV & $0.20 \pm 0.02$ & - \\
ZnO-N & $0.11 \pm 0.02$ & - \\
\hline
\end{tabular}

to $\mathrm{C}-\mathrm{O}-\mathrm{H}$ bonding. The stretching of two $\mathrm{O}-\mathrm{C}$ bonds is exhibited by the band at $1020 \mathrm{~cm}^{-1}$. The analysis of Jamdagni also strengthens our spectral results, who gained FTIR peeks at $3340.6,3258.2,2127.8,1641.1,1456.7,1362.5,1040,1026.8$, 746.25 , and $620.65 \mathrm{~cm}^{-1}$ for $\mathrm{ZnO}$ nanocomposites [34].

3.4. UV-Vis Analysis. UV-Vis spectrographs were taken in the range of $280-500 \mathrm{~nm}$ for $\mathrm{ZnO}$ nanocomposites using suitable solvents. UV absorption spectra for $\mathrm{ZnO}$ nanocomposites with BAV, WAV, and nuts are shown in Figure 5. It is revealed that $\lambda_{\max }$ is shown at 320 and $310 \mathrm{~nm}$, respectively. Nearly, the same results were reported in the previous work [34].

3.5. SEM Imaging. SEM images of $\mathrm{ZnO}$-nanocomposites have been performed on FEI Nova 450 NanoSEM. The shape of each Figure (Figures 6(a), 6(b), 6(c)) obtained by SEM images are fibrous-wired structure, scattered particle, and octahedral, respectively. The different surface morphology of $\mathrm{ZnO}$ nanocomposite revealed that $\mathrm{ZnO}-\mathrm{BAV}$ showed fibrous-wired structure ( 27 to $71 \mathrm{~nm}$ particle size), $\mathrm{ZnO}-\mathrm{N}$ showed scattered particle formation $(\sim 32$ to $83 \mathrm{~nm}$ particle size), and $\mathrm{ZnO}-\mathrm{WAV}$ showed octahedral zinc composite ( $\sim 29$ to $75 \mathrm{~nm}$ particle size) as shown in Figure 6 .

3.6. Antimicrobial Activity. Antimicrobial potential of synthesized $\mathrm{ZnO}$-nanocomposites was investigated against two bacterial strains, i.e., Burkholderia stabilis and Escherichia coli. After preparing Petri plates using agar medium and uniformly distributing the bacterial strains over the agar surface, the disc diffusion method was applied. DMSO was used to make the solutions. The zone of inhibition in case of zinc oxide nanocomposites, as shown in Figure 7, revealed active antimicrobial potency against the selected strains of bacteria. Zone of inhibitions for $\mathrm{ZnO}$ nanocomposites are compared in Table 1.

\section{Conclusion}

Nanocomposites of zinc oxide were synthesized by using the plant extract of Aloe vera and Terminalia plants. These nanoparticles are synthesized under ecofriendly conditions with less toxic chemical production. Nanoparticles are then characterized by using different analytical techniques such as FTIR, UV-VIS, and SEM. In FTIR studies, the synthesized nanoparticles showed absorbance and bending at expected specific wavenumbers due to various functional groups which confirmed the synthesis of nanocomposites. In the UV-Vis, spectrum the synthesized products showed the maximum absorption at specific wavelength assigned for $\mathrm{ZnO}$ that confirms the formation of the product of interest. From SEM images, the nanoparticle's structure was further confirmed, and it shows the morphology of the nanoparticles. Then, the antibacterial potential was checked against two bacterial strains Burkholderia stabilis and Escherichia coli, and both types of nanocomposites indicated efficient antibacterial potency.

\section{Data Availability}

All data related to this work are presented in the Results section along with references.

\section{Conflicts of Interest}

The authors declare that they have no conflicts of interest regarding the publication of this paper.

\section{Acknowledgments}

The Authors are thankful to the home department for providing facilities for this work. 


\section{References}

[1] A. B. Moghaddam, T. Nazari, J. Badraghi, and M. Kazemzad, "Synthesis of $\mathrm{ZnO}$ nanoparticles and electrodeposition of polypyrrole/ZnO nanocomposite film," Intrenational Journal of Electrochemical Science, vol. 4, no. 2, pp. 247-257, 2009.

[2] A. Tripathi, N. Chandrasekaran, A. M. Raichur, and A. Mukherjee, "Antibacterial applications of silver nanoparticles synthesized by aqueous extract of Azadirachta indica (Neem) leaves," Journal of Biomedical Nanotechnology, vol. 5, no. 1, pp. 93-98, 2009.

[3] B. K. Vogler and E. Ernst, "Aloe vera: a systematic review of its clinical effectiveness," British Journal of General Practice, vol. 49, no. 447, pp. 823-828, 1999.

[4] B. Vázquez, G. Avila, D. Segura, and B. Escalante, "Antiinflammatory activity of extracts from aloe vera gel," Journal of Ethnopharmacology, vol. 55, no. 1, pp. 69-75, 1996.

[5] C. Ramteke, T. Chakrabarti, B. K. Sarangi, and R. A. Pandey, "Synthesis of silver nanoparticles from the aqueous extract of leaves of Ocimum sanctum for enhanced antibacterial activity," Journal of Chemistry, vol. 2013, Article ID 278925, 7 pages, 2013.

[6] D. Ramkumar and S. S. C. Rao, "Efficacy and safety of traditional medical therapies for chronic constipation: systematic review," The American Journal of Gastroenterology, vol. 100, no. 4, pp. 936-971, 2005.

[7] F. Capasso, F. Borrelli, R. Capasso et al., "Aloe and its therapeutic use," Phytotherapy Research: An International Journal Devoted to Pharmacological and Toxicological Evaluation of Natural Product Derivatives, vol. 12, no. S1, pp. S124-S127, 1997.

[8] F. Rataboul, C. Nayral, M. J. Casanove, A. Maisonnat, and B. Chaudret, "Synthesis and characterization of monodisperse zinc and zinc oxide nanoparticles from the organometallic precursor [ $\left.\mathrm{Zn}\left(\mathrm{C}_{6} \mathrm{H}_{11}\right)_{2}\right]$," Journal of Organometallic Chemistry, vol. 643-644, pp. 307-312, 2002.

[9] G. A. Ozin, "Nanochemistry: synthesis in diminishing dimensions," Advanced Materials, vol. 4, no. 10, pp. 612-649, 1992.

[10] J. L. Gardea-Torresdey, E. Gomez, J. Peralta-Videa et al., "Formation and growth of Au nanoparticles inside live alfalfa plants," Nano Letters, vol. 2, no. 4, pp. 397-401, 2002.

[11] H. J. Zhai, W. H. Wu, F. Lu, H. S. Wang, and C. Wang, "Effects of ammonia and cetyltrimethylammonium bromide (CTB) on morphologies of $\mathrm{ZnO}$ nano- and micromaterials under solvothermal process," Materials Chemistry and Physics, vol. 112, no. 3, pp. 1024-1028, 2008.

[12] J. F. Jennifer, "Aloe for AIDS," Medical Anthropology, vol. 11, pp. 498-504, 1997.

[13] J. J. Wu and S. C. Liu, "Low-temperature growth of wellaligned $\mathrm{ZnO}$ nanorods by chemical vapor deposition," $A d$ vanced Materials, vol. 14, no. 3, pp. 215-218, 2002.

[14] J. P. Yadav, S. Kumar, L. Budhwar, A. Yadav, and M. Yadav, "Characterization and antibacterial activity of synthesized silver and iron nanoparticles using aloe vera," Journal of Nanomedicine and Nanotechnology, vol. 7, no. 384, p. 2, 2016.

[15] J. R. Morones, J. L. Elechiguerra, A. Camacho et al., "The bactericidal effect of silver nanoparticles," Nanotechnology, vol. 16, no. 10, pp. 2346-2353, 2005.

[16] K. N. Thakkar, S. S. Mhatre, and R. Y. Parikh, "Biological synthesis of metallic nanoparticles," Nanomedicine: Nanotechnology, Biology and Medicine, vol. 6, no. 2, pp. 257-262, 2010.
[17] K. Okuyama and W. W. Lenggoro, "Preparation of nanoparticles via spray route," Chemical Engineering Science, vol. 58, no. 3-6, pp. 537-547, 2003.

[18] M. Bitenc, M. Marinšek, and Z. Crnjak orel, "Preparation and characterization of zinc hydroxide carbonate and porous zinc oxide particles," Journal of the European Ceramic Society, vol. 28, no. 15, pp. 2915-2921, 2008.

[19] P. Mohanpuria, N. K. Rana, and S. K. Yadav, "Biosynthesis of nanoparticles: technological concepts and future applications," Journal of Nanoparticle Research, vol. 10, no. 3, pp. 507-517, 2008.

[20] M. Rai, A. Yadav, and A. Gade, "CRC 675-Current trends in phytosynthesis of metal nanoparticles," Critical Reviews in Biotechnology, vol. 28, no. 4, pp. 277-284, 2008.

[21] M. Singhal, V. Chhabra, P. Kang, and D. O. Shah, "Synthesis of $\mathrm{ZnO}$ nanoparticles for varistor application using $\mathrm{Zn}$ substituted aerosol OT microemulsion," Materials Research Bulletin, vol. 32, no. 2, pp. 239-247, 1997.

[22] P. Chithra, G. B. Sajithlal, and G. Chandrakasan, "Influence of aloe vera on the healing of dermal wounds in diabetic rats," Journal of Ethnopharmacology, vol. 59, no. 3, pp. 195-201, 1998.

[23] P. Jamdagni, P. Khatri, and J. S. Rana, "Green synthesis of zinc oxide nanoparticles using flower extract of Nyctanthes arbortristis and their antifungal activity," Journal of King Saud University Science, vol. 30, no. 2, pp. 168-175, 2018.

[24] P. J. P. Espitia, N. D. F. F. Soares, J. S. D. R. Coimbra, N. J. de Andrade, R. S. Cruz, and E. A. A. Medeiros, "Zinc oxide nanoparticles: synthesis, antimicrobial activity and food packaging applications," Food and Bioprocess Technology, vol. 5, no. 5, pp. 1447-1464, 2012.

[25] P. Sukumaran and E. K. Poulose, "Silver nanoparticles: mechanism of antimicrobial action, synthesis, medical applications, and toxicity effects," International Nano Letters, vol. 2, no. 1, pp. 1-10, 2012.

[26] R. Dobrucka and J. Długaszewska, "Biosynthesis and antibacterial activity of $\mathrm{ZnO}$ nanoparticles using Trifolium pratense flower extract," Saudi Journal of Biological Sciences, vol. 23, no. 4, pp. 517-523, 2016.

[27] S. Dwivedi and M. P. Agarwal, "Antianginal and cardioprotective effects of Terminalia arjuna, an indigenous drug, in coronary artery disease," The Journal of the Association of Physicians of India, vol. 42, no. 4, pp. 287-289, 1994.

[28] S. Dwivedi, “Terminalia arjuna wight \& Arn.-a useful drug for cardiovascular disorders," Journal of Ethnopharmacology, vol. 114, no. 2, pp. 114-129, 2007.

[29] S. Rajasekaran, K. Sivagnanam, K. Ravi, and S. Subramanian, "Hypoglycemic effect of aloe vera gel on streptozotocin-induced diabetes in experimental rats," Journal of Medicinal Food, vol. 7, no. 1, pp. 61-66, 2004.

[30] S. Senapati, A. Ahmad, M. Sastry, R. Kumar, and R. Kumar, "Extracellular biosynthesis of bimetallic Au-Ag alloy nanoparticles," Small, vol. 1, no. 5, pp. 517-520, 2005.

[31] S. Sabir, M. Arshad, and S. K. Chaudhari, "Zinc oxide nanoparticles for revolutionizing agriculture: synthesis and applications," The Scientific World Journal, vol. 2014, Article ID 925494, 8 pages, 2014.

[32] T. Klaus, R. Joerger, E. Olsson, and C. G. Granqvist, "Silverbased crystalline nanoparticles, microbially fabricated," Proceedings of the National Academy of Sciences, vol. 96, no. 24, pp. 13611-13614, 1999.

[33] X. L. Hu, Y. J. Zhu, and S. W. Wang, "Sonochemical and microwave -assisted synthesis of linked single-crystalline 
ZnO rods," Materials Chemistry and Physics, vol. 88, no. 2-3, pp. 421-426, 2004.

[34] Y. L. Wei and P. Chang, "Characteristics of nano zinc oxide synthesized under ultrasonic condition," Journal of Physics and Chemistry of Solids, vol. 69, no. 2-3, pp. 688-692, 2008. 